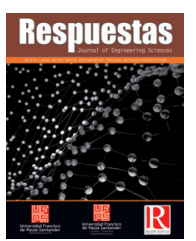

Original Article

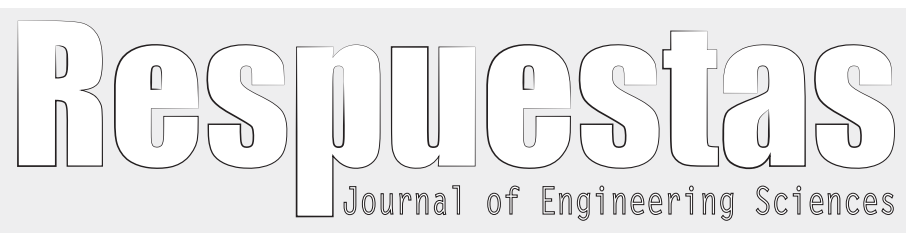

https://doi.org/10.22463/0122820X.1794

\title{
Evaluation of the plastic injection machine maintenance system through the TOPSIS method
}

Evaluación del sistema de mantenimiento de la máquina de inyección de plástico mediante el método TOPSIS Jesús Manuel Calvillo-Guevara ${ }^{1}$, Luis Pérez-Domínguez ${ }^{2 *}$, Luz Angélica Garcia-Villalva ${ }^{3}$

Ingeniero en Mecatrónica, Al122192@alumnos.uacj.mx, ORCID: 0000-0001-7199-2113, Universidad Autónoma de Ciudad Juárez, Ciudad de Juárez, México.

2*Doctor en Ciencias en Ingeniería, Luis.dominguez@uacj.mx, ORCID: 0000-0003-2541-4595, Universidad Autónoma de Ciudad Juárez, Ciudad de Juárez, México. ${ }^{3}$ Magister en Manufactura, lugarcia@uacj.mx, ORCID: 0000-0003-3112-8771, Universidad Autónoma de Ciudad Juárez, Ciudad de Juárez, México.

How to cite: J. Calvillo-Guevara, L Pérez-Domínguez y L. Garcia-Villalva, "Evaluation of the plastic injection machine maintenance system through the TOPSIS method". Respuestas, vol. 24, no. 1, pp. 22-32, 2019.

Received on April 09, 2018; Approved on September 10, 2018

\begin{tabular}{|c|c|}
\hline & ABSTRACT \\
\hline \multirow{5}{*}{$\begin{array}{l}\text { Keywords: } \\
\text { Efficiency } \\
\text { Evaluation } \\
\text { Machines } \\
\text { Manufacturing } \\
\text { Methods } \\
\text { Processes } \\
\text { TOPSIS }\end{array}$} & The following document talks about the parameters of the maintenance system implemented in plastic \\
\hline & injection machines of a maquiladora company located in Ciudad Juarez Chihuahua. The method used in \\
\hline & using measurable collected in said company. With this evaluation the plastic injection machine is determined \\
\hline & in better conditions, as well as the machine in worse conditions, which helps management to make better \\
\hline & RESUMEN \\
\hline Palabras clave: & El siguiente documento habla sobre los parámetros del sistema de mantenimiento implementado en las \\
\hline Eficiencia & $\begin{array}{l}\text { máquinas de inyección de plástico de una empresa maquiladora ubicada en Ciudad Juárez Chihuahua. El } \\
\text { método utilizado en esta investigación es esencialmente la toma de decisiones multicriterio, la técnica para el }\end{array}$ \\
\hline Métodos & condiciones, lo que ayuda a la dirección a tomar mejores decisiones respecto a cada máquina. El objetivo de \\
\hline Procesos & esta investigación es abordar el estudio de la toma de decisiones en el campo industrial específicamente en \\
\hline TOPS & \\
\hline
\end{tabular}

\section{Introduction}

Industrial processes are characterized by carrying out the transformation of raw material into finished product. Similarly, in the search for competitiveness of companies in the field of manufacturing, the interest of the analysis of the machines that are part of these industrial processes has emerged, since they directly influence the quality of the finished product. In general, the plastic injection process is an irreversible physical process, in which raw material such as resin also called thermoplastic is melted, by the effect of heat by means of an injection machine. Thus, the plastic injection process is one of the most common mass production worldwide, because it manifests low cost and high efficiency [1]. In this sense, to achieve a good efficiency of the machines it is necessary to

*Corresponding author.

E-mail address: luis.dominguez@uacj.mx (Luis Pérez Domínguez)

(c) $\Theta \Theta$ Peer review is the responsibility of the Universidad Francisco de Paula Santander.

(c) 
have an optimal maintenance system, since the main maintenance function is to maintain the functionality of the equipment and the good condition of the machines over time [2].

The following work is intended to evaluate a maintenance system applied to a set of plastic injection machines, with the main objective of using the TOPSIS method, evaluating the measurable of the different machines to determine their efficiency, quality and productivity. The main objective of maintenance is to achieve the reliability of the desired system while minimizing the cost [3]. There are several maintenance options, depending on the process specifications, maintenance systems are presented. In the company a preventive maintenance plan is established, in it the frequency of maintenance application is established. The downtime of the machines of this company has very high times, so through TOPSIS it is intended to evaluate the parameters of four plastic injection machines, make a list in order of efficiency, through which the machines are identified in better conditions and in this way suggest changes in the maintenance plan, specifically to the frequency of preventive maintenance assigned to each machine. The similarity order preference method can be used to facilitate the level of management in maintenance managers [4].

Likewise, the literature indicates that the maintenance system can be evaluated through multicriteria decision analysis. Therefore, with respect to the technique method for the order of preference for similarity to the ideal solution called TOPSIS (Technique for Order Preference by Similarity to Ideal Solution, for its acronym in English), this method is planned to be used for the development of present document, to perform the evaluation of plastic injection machines, in order to estimate their optimal operation.

Every day we see ourselves in situations that make us make decisions and in most cases we do it automatically, but when we talk about industrial processes, the literature indicates that relying on mathematical models of decision making is a viable option [5]. Decision making is the process of finding the best option of all feasible alternatives. The TOPSIS method is responsible for performance classifications and the criteria weights are given as well-defined values.

A study has been found where the application is made in a cigarette manufacturing company where the combination of two methods is made, Hierarchical Process Analysis (AHP) and the Technique for the Order of Preference for Similarity to Ideal Solution (TOPSIS), by which is sought determines the most appropriate maintenance system for the manufacturing conditions of the tobacco industry, as well as facilitating maintenance managers in making decisions and proposing maintenance strategies. The result of the investigation shows that conditionbased maintenance (CBM) is the optimal system in cigarette manufacturing companies specifically [5]. On the other hand, studies have been conducted for the optimization of discrete maintenance, which turns out to be a viable method for practical use. The special benefit of the method is that it allows you to optimize not only preventive maintenance but also corrective maintenance, where the repair time parameters can be optimized. It is concluded that, in many practical situations, the characteristics of preventive and corrective maintenance have considerable potential to be modified and improved by applying flexible maintenance equipment [6]. Likewise, they have been raised through a maintenance analysis, regarding time and cost of repair. In particular, the study proposes a cost-based analysis to identify the component or group of components that should be selected [7]. With the same objective, a study is carried out to estimate the costs of performancebased support contracts attributed to corrective maintenance. The approach developed allows a comparative evaluation of the contract solutions and allows for efficient planning decisions. Emphasis is placed on learning from feedback, testing and validating current methodologies to estimate corrective maintenance costs and availability at the type of equipment level [11].

In addition, it is checked through a case study in opportunistic preventive maintenance programming, where the system is evaluated in search of obtaining optimal preventive maintenance, which 
is characterized by improving quality, as well as minimizing the total maintenance cost, including minimum repair cost and costs related to the PM. The proposed methodology is applied to a parallel threestage series machining system [8]. On the other hand, the philosophy of new maintenance knowledge was developed through literature, which should focus on two aspects of knowledge. 1) What can be known and 2) what should be known, to allow maintenance decision makers to take appropriate action. The main objective is the discovery of maintenance knowledge with a focus on Big Data and analysis. The concept is called Maintenance Analytics (MA). MA addresses the process of discovery, understanding and communication of maintenance data based on four perspectives related to time, these are, 1) "Descriptive analysis of maintenance (monitoring)"; 2) "Maintenance Diagnostic Analysis"; 3) "Predictive maintenance analysis"; and 4) "Prescriptive analytical maintenance" [9].

On the other hand, in a real manufacturing scenario in the automotive lighting equipment industry, a proactive event-based decision model is proposed for predictive maintenance and the optimization of spare parts inventory, which addresses the decision phase of the "Detect-Predict-Decide-Act" model and can be managed in an Event-driven Architecture (EDA). The investigation showed that maintenance costs, as well as inventory costs, can be significantly reduced by transforming the maintenance strategy of the industry. Time-based maintenance (CBM) proved to be the ideal proposal [10].

Similarly, through numerical examples and sensitivity studies, an analytical model is developed to simultaneously determine the optimal values of two decision variables: the number of batches produced before performing the imperfect PM and the amount of imperfect PM actions that are they must undertake before applying a perfect maintenance action by maximizing the expected total benefit. An analytical model has been developed to determine an optimal preventive maintenance plan, taking into account the quality of the output product and the reprocessing process [14]. On the other hand, the optimization of the block-based maintenance system is considered. In this investigation it is proposed to use a random machine control using a Markov switch (on / off) and present a method to determine the optimum maintenance interval. Several case studies are carried out and the optimal maintenance intervals are compared with two reference intervals resulting from the limiting cases with a very high and very low switching frequency. Through this analysis, the optimum frequency for the execution of preventive maintenance is determined [18]. In the same way, investigations with the same sense are presented, where the preventive maintenance system is developed in a pasta company, based on an investigation, which aims to determine the optimal preventive maintenance period, identify the parts that you provide environmental, social, economic benefits and confirms the need to introduce sustainability considerations in conventional maintenance procedures [17].

Again the automotive industry presents a strategic maintenance study, which consists of performing a series of tasks, in order to prevent failures in the system, as well as to perform repairs. Any section of the process can be analyzed by a simulation of discrete events to predict the distribution of expected term time. The framework has three key elements: identification of the possible tests that can be performed, simulation of a maintenance process with the selected tests integrated to determine the distribution of time for successful completion and finally an optimization phase that allows to select the tests for be able to carry out the process in the shortest time [15]. Likewise, an evaluation of the maintenance system is developed in order to predict the next failure, while at the same time an optimal solution is proposed to reduce the repair and maintenance time. The proposed method is demonstrated by two case studies [16]. In the same way with future research, the Delphi Company conducts studies of evaluation of scenarios in maintenance, planned in the year 2030, through an extensive survey of three rounds with 25 maintenance experts at strategic level of the largest companies within The Swedish manufacturing industry. The highlighted results are collected in 34 projections on the potential changes of the internal and external environment for maintenance organizations. The 
contribution of the study is based on the development of probable scenarios and probable solutions for future maintenance [13]. Through similar studies, literature research is conducted to address the issue of preventive maintenance. It is intended to determine a preventive maintenance system with application in the automotive sector. Solutions were shared to support the company through reliability studies. Therefore, this document helps to reduce the gap identified in the literature between theory and practice, thoroughly analyzing the barriers at each stage of the proposed procedure and reflecting on possible solutions to address them [12].

This research aims to help maintenance managers make the right decisions in plastic injection processes, if they find any maintenance strategy option. To carry out the evaluation of the maintenance system, the company's measurable measures were collected, such as OEE, PPM, SCRAP and SET-UP times. Currently, organizations are looking for a maintenance system that meets the needs of competitiveness in line with the current market. Plastics injection processes need to be competitive both in quality, productivity and reliability with respect to similar companies worldwide. Although the company has a preventive maintenance system, the measurable continue to show results below the proposed goal. The current competitive environment requires that companies are constantly improving, to ensure their permanence in the market by offering superior quality products. It seeks to implement the TOPSIS method to evaluate the maintenance system of plastic injection machines. Currently, quality standards are very high for industrial processes, so maintaining good numbers in these standards are specific objectives of companies. This document aims to perform an evaluation of plastic injection machines in order to know what conditions the system is in, as well as to determine, based on mathematical calculations using the TOPSIS method, multi-criteria decision making. The general objective of this research is to address the study of decision making in the industrial field, specifically in the molding machine maintenance system. This research also seeks to address the following objectives: Represent a maintenance problem in a multi-criteria environment. Use the TOPSIS (Technique for Order Preference by Similarity to Ideal Solution, ) method, evaluating the measurable plastic injection machines. Evaluate the maintenance system. This research focuses especially on the evaluation and classification of the maintenance system using the TOPSIS method. In this sense it is intended to determine an ideal solution based on mathematical operations for this specific topic. Therefore, the scope of this research focuses on decision making in the maintenance system used in plastic injection machines. The objective of this application is essentially to show the results of the evaluation and approximate a proposal based on the TOPSIS method.

Plastic injection molding is suitable for mass production items since complex geometries can be obtained in a single production step. The rapid increase of plastics and their proliferation in all markets has been observed in the last century. In the United States, the plastics industry has increased at a rate of 12 percent per year for the past 25 years, and the main process of plastic transformation is injection molding, followed by extrusion. Polymers have succeeded in replacing materials such as wood, metals, natural fibers, ceramics and even precious stones. According to the world consumption of raw materials by weight, plastic is the highest compared to other old materials such as aluminum, steel, rubber, copper and zinc, as a result of its properties and lower production cost. The final quality of the parts injected in the injection molding depends on the characteristics of the material, the design of the mold and the conditions of the process [19]. There are three fundamental operations in injection molding. First, the plastic granules will become a melt. Then, the molten plastic will be injected into the mold cavity or the cavities under pressure through the trough systems, channels and gates and, finally, the mold tools will open to eject the piece from the cavities [20].

Although injection molding is an established technology with many decades of use, factors such as processed raw material, plasticization quality and processing parameters result in significant variations in product quality. Traditionally, researchers have tried to improve the quality of injection molded 
components by controlling screw position, injection and maintenance pressures, and mold and barrel temperatures. The plasticizing quality in the injection molding process depends on the cutting speed, temperature and pressure during this stage, and manifests essentially in the viscosity of the molten resin [21].

The plastic injection machines have the following important parts to achieve their operation. Injection unit: The main function of the injection unit is to melt, mix and inject the polymer. To achieve this, spindles are used, which vary their characteristics depending on the polymer to be melted. There are three fundamental thermodynamic conditions that must be considered to carry out the study of the function of polymers: The polymer processing temperature. The caloric capacity of the polymer $\mathrm{Cp}$ [cal / g [U + 2103]]. The latent heat of fusion, if the polymer is semi-crystalline. an increase in heat in the polymer is involved through the smelting process, which is caused by the increase in temperature and friction between the barrel and the spindle.

Because polymers are good conductors of heat, friction and shear stresses, they are essential for efficient fusion. The viscosity of the molten polymer decreases due to an increase in temperature, as well as increasing the cutting speed. It is for this reason that the literature suggests that these parameters be adjusted during the process. However, there are standard metals for each polymer in order to avoid corrosion or degradation. The injection unit performs the same function as an extruder, unlike it works with a single spindle, it maintains a desirable temperature set by means of heaters and sensors located in the barrel.

The depth varies between the channel and the spindle, from the feeding zone to the dosing zone, depending on the application in which it is located. in this way the pressure in the barrel gradually increases. There are other factors that intuit the temperature of the system, such as the mechanical shear stress and compression, so the polymer melts more efficiently than just the heat factor. For this reason, it is essential to use the spindle and instead of other methods of obtaining melt.
The molding presents, among other things, a reserve chamber, which differentiates it from the extruder. In said reserve chamber where the molten polymer is stored for later injection. In such a way that the whole unit behaves like the plunger of a piston that pushes the material. In both processes such as molding and extrusion must take into account the PvT Relationships (pressure, volume, temperature).

The main objective of plant maintenance is to achieve a minimum breakdown and keep the plant in good working condition at the lowest possible cost. Therefore, maintenance should not be considered as a cost center, but as a profit-generating function.

Preventive maintenance (PM) is described as the maintenance of equipment or systems before the failure occurs, therefore, not allowing the failure to occur. While preventive maintenance in general is considered worthwhile, there are some disadvantages such as the huge cost and the need for specialized labor. Reliability-centered maintenance (RCM) is one of the most well-known and used devices to preserve operational efficiency in critical sectors such as power plants, artillery system, aviation industry, rail networks and the oil industry.

Maintenance is responsible for improving the productivity of all processes, therefore, effective maintenance is very helpful for organizations [22]. Among the advantages of effective maintenance are, prolong the life of the equipment, better the availability of equipment and keep the equipment in proper condition. The productivity and profitability of a production process are impacts presented by the quality policy. In such a way that through effective maintenance you can increase the profits of the company to the best efficiency, effectiveness and productivity of manufacturing processes. Therefore, effective maintenance can contribute significantly to increasing the availability, reliability and profitability of the plant, which leads to an efficient and sustainable improvement in performance [23].

Sustainable performance improvement. Senior management is being provoked by intense competitive pressure to see the performance of each of the business functions, be it production 
or maintenance, or any other business function to achieve competitive advantage [24]. One of the main objectives of the companies is profitability, not only in the near future, but in the entire useful life of the company without having an adverse impact on society. This requires the company to rely on changing customer requirements. It requires safe and profitable operations throughout the life of the asset and that requires sustainable and effective performance. The main factors to improve performance are reliability, productivity and sustainability. This can be achieved through effective maintenance systems.

Regarding sustainable growth, it has been observed that people's safety, environment and resource management are very important points for any organization [24]. Through adequate security programs, it is possible to protect companies from financial losses [25]. The maintenance department must work towards the creation of a safe workplace, since maintenance work is often critical to the operator's health. Initially, the purpose of periodic maintenance was to increase overall safety rather than improve availability or cost reduction, or increase performance [26]. Security includes personal and process security. Process safety is of greater importance as it can prevent major disasters, potentially with multiple deaths [24].

The quality of a product is the main characteristic used by customers to select a product or service [27]. In such a way, that a company's quality policy determines its growth prospects. Through quality policy, companies publicize the mission of the organization. To reduce the product rejection rate, the quality management system and the maintenance system must be integrated [28].

All production planning is affected by the breakdown of the machine. Breakage losses can be classified into two types: equipment failures that lead to time losses when productivity is reduced and defective products that lead to quantity losses. The literature indicates that, to overcome a situation of rupture, organizations need to maintain higher inventories and thus add the cost. When a machine breaks down, the production process is interrupted and, therefore, affects the effectiveness of the plant. The willingness to deal with such events is influenced by the decisions of senior management [29].

The delivery time of the process can be reduced by the practice of efficient maintenance management [30]. It has been proven that the decrease in delivery time is one of the reasons to invest in maintenance improvements. Effective maintenance helps reduce downtime and minor downtime. To reduce the waiting time, the process needs to control faults through effective machine maintenance. To reduce downtime, machine failures must be minimized [31].

Quality is one of the competitive metrics worldwide, as well as cost and superior performance in the wide range of products. The main maintenance objective is to increase quality standards, while reducing the occurrence of breakdowns. Maintenance should not be considered as a cost center, but as a profitgenerating function [29].

Method TOPSIS (Technique for Order Preference by Similarity to Ideal Solution).

TOPSIS, developed by Hwang and Yoon in 1981, is a simple method of classification in conception and application. This technique is based on the comparison between all the alternatives included in the problem. This proposed technique can be very useful in large-scale decision-making problems, as often found in industrial processes. This technique is based on positive and negative ideal solutions, determined in relation to the distance of each alternative to the best or worst alternatives. The ideal alternative not necessarily observed is determined from the best values of the set of alternatives in which way the anti-ideal alternative is determined from the worst values of the set of alternatives.

\section{Case study}

This is a case study taking data from a maquiladora company in Ciudad Juárez where there is a need to evaluate the performance of plastic injection machines to propose continuous improvement strategies. Thus, a set of four machines and four criteria is proposed.

Demag $85 \mathrm{~T}$, this is the number one alternative, it is a plastic injection machine which has an injection 
pressure of 85 tons, clamping force of $1000 \mathrm{kn}$ and a heating capacity of $11.1 \mathrm{k}$.

Cincinnati $85 \mathrm{~T}$, the Cincinnati machine is the second alternative, it is a plastic injection machine which has an injection power of 85 tons.

Toshiba 220T, the third option is the Toshiba machine which has an injection pressure of 220t, how much with a screw diameter: $50 \mathrm{~mm}$, makes a stroke opening: $800 \mathrm{~mm}$, produces an injection volume: $490 \mathrm{~cm}^{3}$ and a weight $450 \mathrm{~g}$ shooting.

Nissi 250t, the fourth option is consists of an injection pressure of 250 tons.

\section{Evaluation criteria}

The set of criteria involved in the problem are the following: Total team effectiveness (OEE), is a performance measurement metric that will indicate the rate of return with very simple calculations. Consider all important productivity measures. The OEE is one of the measurable that is intended to be assessed in the present investigation, the OEE percentage of the company's monitoring system was taken, which is carried out through the Access program. This criterion is used to measure the quality, productivity and availability of the machines, this type of criterion is quantitative. It is the criterion represented by $\mathrm{C} 1$.

Preparation time, this criterion throws us the waiting times in the changes part numbers, the criterion is quantitative. This criterion is represented by $\mathrm{C} 2$.

Operation time, this criterion gives us information about the running time of the machine per piece generated. This type of criterion is quantitative. This criterion is represented by C3.

Parts per million (PPM), in the current market environment, both in the engineering and nonengineering industries, it considers a ppm indicator as one of the most important in the evaluation of the efficiency of its processes. [32]. his criterion tells us the pieces per million produced with a quality that does not approve the quality criteria.
This criterion is evaluated qualitatively. In turn, this criterion is represented by $\mathrm{C} 4$.

Waste (Scrap), this criterion indicates the waste generated by the process. This criterion was evaluated qualitatively. This criterion is represented by $\mathrm{C} 5$.

Step one. The first step to present the TOPSIS method is, definition of the decision matrix, which consists in defining the set of alternatives, set of criteria and their weight of each of them, as well as the values of each attribute in each alternative.

The established matrix consists of $m$ alternatives and $\mathrm{n}$ criteria with the intersection of each alternative and criteria given as $\mathrm{x}_{\mathrm{ij}}$, and therefore have a matrix $\left(\mathrm{x}_{\mathrm{ij}}\right) \mathrm{mxn}$.

The decision matrix described in step one is made and presented in Table I.

Step two. Once the decision matrix is defined, we proceed to normalize the decision matrix, which consists in dividing each component by the norm of the column vector of which it is part $\left(\mathrm{v}_{\mathrm{j}}\right)$. The normalization of the vector.

By applying equation (1) as shown in step two, the decision matrix is normalized and shown in Table II.

Step three. it consists of constructing the weighted standardized decision matrix, which means weighing each value by the weight of each criterion.

Subsequently, the weighted standardized decision matrix is determined using equation (2) described in step three, and is shown in Table III.

Table I. Set of decisions
\begin{tabular}{|c|c|c|c|c|c|}
\hline MACHINES & C1 & C2 & C3 & C4 & C5 \\
\hline DEMAG 85 TON & $78.71 \%$ & 1.2 & 0.0067 & 2 & 5 \\
\hline $\begin{array}{c}\text { CINCINNATI 85 } \\
\text { TON }\end{array}$ & $81.21 \%$ & 1.0834 & 0.0055 & 4 & 2 \\
\hline TOSHIBA 220 TON & $83.75 \%$ & 1.5 & 0.0122 & 3 & 3 \\
\hline NISSI 250 TON & $91.46 \%$ & 1.3034 & 0.0092 & 3 & 3 \\
\hline
\end{tabular}

Step four. Having these steps established we can proceed to determine the positive ideal alternative (SIP) and the anti-ideal or negative ideal alternative (SIN), which consists of selecting the best value for ideal alternative from among the values given for the

$Z_{i j}=\emptyset_{i j} / \sqrt{\sum_{k}^{m} \emptyset_{i j}^{2}}, i=1,2, \ldots, m j=1,2, \ldots, n$ 
attributes in each alternative and the worst for the anti-ideal.

Table II. Vector normalization
\begin{tabular}{|c|c|c|c|c|}
\hline C1 & C2 & C3 & C4 & C5 \\
\hline $\mathbf{1 . 6 7 8 3}$ & 2.5618 & 0.0176 & 6.1644 & 6.8556 \\
\hline
\end{tabular}

Equations (3) and (4) help us determine the positive ideal alternative and the negative ideal alternative

$$
\Delta_{i j}=\varepsilon_{j} \times z_{i j} \text { is the criterion preference } j
$$

respectively, described in step four and can be seen in Table IV.

Table III. Weighted standardized decision matrix
\begin{tabular}{|c|c|c|c|c|}
\hline C1 & C2 & C 3 & C4 & C5 \\
\hline $\mathbf{0 . 0 9 3 8}$ & 0.0937 & 0.0767 & 0.0649 & 0.1459 \\
\hline $\mathbf{0 . 0 9 6 8}$ & 0.0846 & 0.0625 & 0.1298 & 0.0583 \\
\hline $\mathbf{0 . 0 9 9 8}$ & 0.1171 & 0.1388 & 0.0973 & 0.0875 \\
\hline $\mathbf{0 . 1 0 9 0}$ & 0.1018 & 0.1046 & 0.0973 & 0.0875 \\
\hline
\end{tabular}

Step five. This step focuses on the calculation of distance measurements, which would be to calculate the distances of each alternative to the ideal and antiideal solution, these measures are summarized by a vector.

$$
\begin{aligned}
& \beta^{+}=\left(\max , \Delta_{i j} \mid j \in J\right),\left(\min _{i} \Delta_{i j} \mid j \in J\right) \\
& \beta^{-}=\left(\min _{i} \Delta_{i j} \mid j \in J\right),\left(\max , \Delta_{i j} \mid j \in J\right)
\end{aligned}
$$

With equations (5) and (6) the distances of the positive ideal solution and the ideal negative solution are calculated respectively and are shown in Table V.

Table IV. Determination of the positive ideal alternative (SIP) and the antiideal alternative (SIN)

\begin{tabular}{|c|c|c|c|c|c|}
\hline COMPOSITION & C1 & C2 & C3 & C4 & C5 \\
\hline $\mathbf{A}+$ & 0.1090 & 0.0846 & 0.0625 & 0.0649 & 0.0583 \\
\hline $\mathbf{A}-$ & 0.0938 & 0.1171 & 0.1388 & 0.1298 & 0.1459 \\
\hline
\end{tabular}

Step six. It consists in the calculation of the relative proximity to the ideal alternative.

By means of equation (6) the relative proximity to the ideal alternative is realized which is expressed in Table VI.

$$
\begin{aligned}
& \alpha_{i}^{+}=\sqrt{\sum_{j=1}^{n}\left(\Delta_{i j}-\Delta_{j}^{+}\right)^{2} i=1,2,3, \ldots, m} \\
& \alpha_{i}^{-}=\sqrt{\sum_{j=1}^{n}\left(\Delta_{i j}-\Delta_{j}^{-}\right)^{2} i=1,2,3, \ldots, m}
\end{aligned}
$$

Step seven. Finally, we sort the data in descending order, major to minor [33].

Table V. Calculation of the distances of each alternative to the ideal and antiideal solution

\begin{tabular}{|c|c|c|}
\hline Machinery & $\mathbf{s}^{+}$ & $\mathbf{s}^{-}$ \\
\hline DEMAG 85 TON & 0.0904 & 0.0928 \\
\hline CINCINNATI 85 TON & 0.0660 & 0.1206 \\
\hline TOSHIBA MOLDING MACHINE & 0.0942 & 0.0670 \\
\hline NISSI & 0.0630 & 0.0780 \\
\hline
\end{tabular}

\section{Results and Discussions}

$$
c_{i}^{+}=\alpha_{i}^{-} /\left(\alpha_{i}^{-}+\alpha_{i}^{+}\right) \quad i=1,2,3, \ldots, m
$$

Where $0 \leq c_{i}+\leq 1$

This section shows the results that were obtained:

Table VI. Calculation of the relative proximity to the ideal alternative

\begin{tabular}{|c|c|}
\hline Machinery & $\mathbf{C i}$ \\
\hline DEMAG 85 TON & 0.50655331 \\
\hline CINCINNATI 85 TON & 0.646319069 \\
\hline TOSHIBA MOLDING MACHINE & 0.41567289 \\
\hline NISSI & 0.553161144 \\
\hline
\end{tabular}

Table VII shows the results of the order of the alternatives.

Table 7 shows the ranking of machines evaluated by TOPSIS. First is the Cincinnati plastics injection machine. It should be noted that this machine is the longest, which does not influence efficiency as, according to the study, it is the machine in better conditions. The TOSHIBA machine, on the other hand, is the machine that presents the

Table VII. Order of the alternatives

\begin{tabular}{|c|c|c|}
\hline Machinery & Ci & Ranking \\
\hline CINCINNATI 85 TON & 0.6463 & 1 \\
\hline NISSI & 0.5531 & 2 \\
\hline DEMAG 85 TON & 0.5065 & 3 \\
\hline TOSHIBA MOLDING MACHINE & 0.4156 & 4 \\
\hline
\end{tabular}

greatest opportunity for improvement. Therefore, management is recommended to pay more attention to this machine. 


\section{Conclusions}

A case study is presented where multi-criteria application in the maintenance system, specifically in plastic injection machines. Based on the analysis that has been performed, it can be concluded that the Cincinati machine has the best conditions and in turn the Toshiba machine the worst conditions, due to the evaluation of the maintenance system parameters. With this evaluation the level of management can be facilitated, especially in maintenance managers, which can help in decision making and continuous improvement applied to plastic injection machines.

Based on the results obtained, it is suggested to carry out future studies, specifically in the maintenance plan, this in order to program the plan of optimal preventive maintenance of the company, considering the current conditions of the machines.

Likewise, it is observed that the TOPSIS method systematically proposes the evaluation of machine maintenance. On the other hand, it is suggested to generate other experiments with other methods to assess the results.

\section{References}

[1] J-Y. Chen, K-J. Yang and M-S. Huang, "Online quality monitoring of molten resin in injection molding", International Journal of Heat Mass Transfer, pp. 681-693, 2018.

[2] A. Gutierrez, "Mantenimiento, planeación, ejecucion y control", Alfaomega Grupo Editor, Mexico, 2009.

[3] M. Kobbacy, "Complex System Maintenance Handbook", Springer: Springer Series in Reliability Eng, 2008.

[4] L. Swason, "An information-processing model of maintenance management", International Journal of Production Economics, pp. 45-64, 2003.

[5] A. Nurcahyo, "Maintenance Program Selection in Cigarette Manufacturing Industry With Multi-Criteria Decision-Making
Method", IEEE International Conference on Engineering Technologies and Applied Sciences (ICETAS), 2017.

[6] P. B. Radim-Bris, "Discrete maintenance optimization of complex multi components systems", Reliability Energinering and Systems Safety, pp. 80-89, 2017.

[7] S. R. C. Y. Hongyan-Dui, "A cost-based integrated importance measure of system components for preventive maintenance", Reliability Engineering \& System Safety, vol. 168, pp. 98-104, 2017.

[8] X. Z. Biao-Lu, "Opportunistic preventive maintenance scheduling for serial-parallel multistage manufacturing systems with multiple streams of deterioration", Reliability Engineering \& System Safety, vol. 168, pp. 116-127, 2017.

[9] J. W. G. U. K. Ramin-Karim, "Maintenance Analytics - The New Know in Maintenance", International Federation of Automatic Control, pp. 214-219, 2016.

[10] A. B. N. P. B. M. D. A. G. Mentzas, "A Proactive Event-driven Decision Model for Joint Equipment Predictive Maintenance and Spare Parts Inventory Optimization", de The 5th International Conference on Through-life Engineering Services (TESConf 2016), 2017.

[11] J. Ahmet-Erkoyuncua, et al., "Perspectives on trading cost and availability for corrective maintenance at the equipment type level", Reliability Engineering \& System Safety, vol. 168, pp. 53-69, 2017.

[12] I. L. J. A. Sandrina-Vilarinho, "Preventive Maintenance Decisions through Maintenance Optimization Models: A Case Study", Procedia Manufacturing, vol. 11, pp. 1170-1177, 2017.

[13] A. S. C. B. J. S. Jon-Bokrantz, "Maintenance in digitalised manufacturing: Delphi-based scenarios for 2030", International Journal of 
Production Economics, vol. 191, pp. 154-169, 2017.

[14] A. G.-M. S. D. Z. A. W. Erray, "Integrated Maintenance-Quality policy with rework process under improved imperfect preventive maintenance", Reliability Engineering \& System Safety, pp. 1-11, 2018.

[15] Y. Z. J. A. S. R. M. Karlberg, "Maintenance processes modelling and optimisation", Reliability Engineering \& System Safety, pp. 150-160, 2017.

[16] Y. C. T. J. Yu-Liu, “On Sequence Planning for Selective Maintenance of Multi-State Systems under Stochastic Maintenance Durations", European Journal of Operational Research, 2018.

[17] C. F. A. L. S. Miranda, "Sustainable Maintenance: $\quad$ a Periodic Preventive Maintenance Model with Sustainable Spare Parts Management", IFAC-PapersOnLine, vol. 50, pp. 13692-13679, 2017.

[18] E. J. Bramde-Jongea, “Optimizing block-based maintenance under random machine usage", European Journal of Operational Research, vol. 265, pp. 703-709, 2018.

[19] M. Altan, "Reducing shrinkage in injection moldings via the Taguchi, ANOVA and neural network methods", Materials \& Design, pp. 599- 604, 2010.

[20] H. Zhou, "Computer Modeling For Injection Molding", A John Wiley \& Sons, Inc., Publication, 2003.

[21] M. S. H. Jian-Yu Chen, "Online quality monitoring of molten resin in injection molding", International Journal of Heat and Mass Transfer, pp. 681-693, 2018.

[22] J. Block, et al., "Part-out-based spares provisioning management: A military aviation maintenance case study", Journal of Quality in Maintenance Engineering, vol. 20, no. 1, pp. 76-95, 2014.
[23] J. M. Simões, F. Gomes and Y. Mahmoud, "Changing role of maintenance in business organisations: Measurement versus strategic orientation", International Journal of Production Research, vol. 54, no. 11, pp. 3329-3346, 2016.

[24] V. Narayan, "Business performance and maintenance", Journal of Quality in Maintenance Engineering, vol. 18, no. 2, pp. 183-195, 2012.

[25] M. S. A. A. H. Shaaban, "Critical success factors for total productive manufacturing (TPM) deployment at Egyptian FMCG companies", Journal of Manufacturing Technology Management, vol. 25, no. 3, pp. 393-414, 2014 .

[26] A. Noroozi, N. Khakzad, F. Khan, S. MacKinnon and R. Abbassi, "The role of human error in risk analysis: Application to pre-and post-maintenance procedures of process facilities", Reliability Engineering \& System Safety, vol. 119, pp. 251-258, 2013.

[27] N. Graham, Y. Dissou and A. Duque, "Managerial role in ensuring successful total quality management programme in Ghanaian printing irms", The TQM Journal, vol. 26, no. 5, pp. 398-410, 2014.

[28] B. Bouslah, A. Gharbi and R. Pellerin "Integrated production, sampling quality control and maintenance of deteriorating production systems with AOQL constraints", Omega, vol. 61, pp. 110-126, 2016.

[29] A. Parida, U. Kumar, D. Galar and C. Stenström, "Performance measurement and management for maintenance: A literature review", Journal of Quality in Maintenance Engineering, vol. 21, no. 1, pp. 2-33, 2015.

[30] A. GosaviSusan, L. Murray, L. Murray, V. Manojramam and S. Shewade, "A budgetsensitive approach to scheduling maintenance in a total productive maintenance (TPM) 
program", Engineering Management Journal, vol. 23, no. 3, pp. 46-56, 2011.

[31] J. Kumar, V. Kumar and G. Agnihotri, "Impact of TPM implementation on Indian manufacturing industry", International Journal of Productivity and Performance Management, vol. 65, no. 1, pp. 44-56, 2014.

[32] L. B. H. Zídková, "Use of the ppm and its function in the production process", Procedia Manufacturing, pp. 608-615, 2017.

[33] J.-J.H. Gwo-Hshiung Tzeng, MultipleAttribute Decision Making: Methods and Applications, New York: Taylor \& Francis Grup, 2011. 